\title{
PESAN TEKS DAN PESAN GAMBAR PADA FOTO NATIONAL GEOGRAPHIC (KAJIAN SEMIOTIK)
}

\author{
Febriana Friza $^{1}$, Yumna Rasyid ${ }^{2}$, Fathiaty Murtadho ${ }^{3}$ \\ Program Megister Pendidikan Bahasa, Universitas Negeri Jakarta \\ ${ }^{1}$ febrianafriza_pb14s2@mahasiswa.unj.ac.id, ${ }^{2}$ yumna.rasyid@unj.ac.id, \\ fathiaty_Murtadho@unj.ac.id ${ }^{3}$
}

\begin{abstract}
Abstrak
Faktor utama kajian dalam penelitian ini adalah bagaimana suatu foto jurnalistik dapat diketahui pesannya baik dilihat dari makna yang sebenarnya (denotatif) dan makna yang tersirat (konotatif). Penelitian ini adalah penelitian kualitatif dengan menggunakan foto National Geographic. Hasil penelitian ini diharapkan dapat mengetahui makna gambar dan kesesuaian antara gambar dan teks pada foto jurnalistik. Agar dapat mengetahui makna yang terkandung dalam foto-foto jurnalistik, penulis menggunakan analisis semiotik. Analisis semiotik adalah metode untuk menganalisis dan memberi makna simbol-simbol yang terkandung dalam gambar atau simbol teks. Hasil penelitian menunjukkan bahwa foto dan teks caption memiliki kesamaan persepsi jika dianalisis dengan menggunakan analisis semiotik.
\end{abstract}

Kata Kunci: Teks, gambar, analisis semiotik, dan foto jurnalistik.

\begin{abstract}
The objective of this research was to understand the purpose of denotative and connotative message. It was qualitative reserach on the based of National Geographic photo. The results of this study are expected to know the meaning of the image and the suitability between the image and text on the photojournalism. To find the meaning contained in journalistic photographs, the author uses the semiotic approach. Semiotic analysis is a method for analyzing and giving meanings it symbols contained in a message or text symbol. The results of the analysis show that photo and caption texts had similar perceptions when analyzed using semiotic analysis.
\end{abstract}

Keywords: teks, images, semiotics analysis, and photojournalism.

\section{PENDAHULUAN}

Suatu peristiwa yang terjadi ditampilkan beragam di media cetak maupun elektronik, baik dalam bentuk tulisan ataupun visual berupa foto. Hal ini bisa menyebabkan terjadinya distorsi dan bias penafsiran oleh pembaca, karena adanya perbedaan sudut pandang antara realitas yang terjadi dengan yang terpampang versi setiap media. Media massa merupakan alat komunikasi yang banyak digunakan untuk menyampaikan berbagai pesan melalui teks dan gambar sebagai pelengkap. Teks sendiri mempunyai fungsi komunikatif sebagai media untuk menyampaikan pesan (message) dari penulis atau penutur kepada pembaca. Pesan itu sendiri akan disampaikan melalui bahasa yang dikenal sebagai sistem lambang yang untuk seseorang berbagi makna. 
Di era digital saat ini media daring menjadi pilihan utama untuk membaca berita karena dapat mudah di akses di mana saja dan kapan saja. Mengutip dari hasil penelitian Lisa Viranda bahwa laporan Survei APJII tahun 2017 menyatakan bahwa 143,26 juta jiwa pengguna internet di Indonesia, sebanyak $49,52 \%$ di antaranya merupakan milenial dengan rentang usia 19-34 tahun. Oleh karena itu, penelitian yang berkaitan dengan dunia daring merupakan sesuatu hal yang baru dan banyak sekali aspek yang bisa diteliti, salah satunya dengan media foto (Viranda, Hidayat, \& Yudhapramesti, 2018). Belum banyak ditemukannya penelitan yang serupa menjadikan penulis tertarik untuk meneliti lebih lanjut tentang pemaknaan sebuah foto, diperkuat juga dengan pernyataan Clark (1997) dalam buku The Photograph, bahwa fotografi dapat dibaca bukan saja dilihat sebagai image, tetapi juga sebagai teks.

Foto atau gambar menjadi magnet tersendiri untuk menarik pembaca utamanya kaum muda yang sekarang biasa disebut kaum milenial. Saat ini fenomena foto menjadi perhatian publik, karena foto mempunyai kemampuan representatif yang sempurna. Dalam hal ini, foto jurnalistik yang menjadi acuan penelitian. Roland Barthes kemudian muncul dengan teorinya yang berkaitan dengan dunia foto atau yang lebih dikenal dengan semiotika konotasi dan biasa disebut juga Barthesian, telah memberi ruang bagi dunia foto jurnalistik untuk menggambarkan pemberitaan (St. Sunardi, 2002). Dengan menggunakan semiotika konotasi, foto media, secara khusus foto jurnalistik (photojournalistic image atau news photography) dapat dibaca atau diketahui maknanya.

Foto ibarat kata kerja tanpa kata dasar (infinity), dalam The Photographic Message Barthes (1977) menyebutkan prosedur atau kemungkinan untuk memengaruhi gambar sebagai analogon. Analogon yaitu apa yang dihasilkan dalam menulis dengan bahasa gambar, menulis dengan bahasa gambar berarti sebuah kegiatan intervensi pada tingkat kode. Menurut Barthes (2010), citra pesan ikonik/iconic message (yang dapat kita lihat, baik berupa adegan/scene, lanskep, atau realitas harfiah yang terekam) dapat dibedakan lagi dalam dua tataran, yaitu:

1. Pesan harfiah/pesan ikonik tak berkode (non-coded iconic message), sebagai sebuah analogon yang berada pada tataran denotasi citra yang berfungsi menaturalkan pesan simbolik.

2. Pesan simbolik/pesan ikonik berkode (coded iconic message), sebagai analogon yang berada pada tataran konotasi yang keberadaannya didasarkan atas kode budaya tertentu atau familiaritas terhadap streotip tertentu. Pada tataran ini, Barthes mengemukakan enam prosedur konotasi citra khususnya menyangkut fotografi untuk membangkitkan konotasi dalam proses produksi foto menurut Roland Barthes, yaitu Trick effect, Pose, Objek, Fotogenia, Aestethicism (estetika), Sintaksis.

Semiotika atau biasa kita sebut dengan semiotik (semiotics) memiliki beberapa definisi dari berbagai ahli bahasa salah satunya Ferdinand de Saussure dalam bukunya course in general linguistics yang menyatakan "A science that studies the life of signs within society is conceivable" yang bisa diterjemahkan sebagai ilmu yang mengkaji tentang tanda sebagai bagian dari kehidupan (Saussure, 1959). Makna implisit pada definisi Saussure, yaitu prinsip bahwa semiotika sangat menyandarkan dirinya pada aturan main (rule) atau kode sosial (social code) yang berlaku di dalam masyarakat, sehingga tanda dapat dipahami maknanya secara kolektif. Salah satu pembahasan tentang semiotik oleh Umberto Eco dikutip oleh buku Teori dan Pengajaran sastra, yaitu (Emzir dan Saifur, 2015): 
Semiotics is concerned with everything that can be taken as a sign. Semiotics involves the study not only of what we refer to as "sign" in everyday speech, but of anything which "stands for" something else. In a semiotics sense, signs take the form of words, images sounds, gestures, and object. Semiotics is concerned with meaning-making and representation in many forms, perhaps most obviously of the form of "texts" and "media". A "text" can be exit in any medium and may be verbal, non-verbal, or both. The term "text" usually refers to a message which has ben recorded in some way (e.g whiting, sounds, images sound, gesture) constructed (and interpreted) with reference on the conventions associated with a genre and in a particular medium of communication.

Artikel yang membahas tentang foto jurnalistik secara deskripif penulis dapatkan dengan judul Visual Bias in Time's "The Great Divide": A Semiotic Analysis of Clinton and Obama Photographs yang ditulis oleh Trischa Goodnow, dalam artikelnya Trischa (Goodnow, 2010) menjelaskan makna foto jurnalistik antara Clinton dan Obama dengan menggunakan kajian semiotik Kress dan van Leeuwen yang menjabarkan secara deskriptif foto tersebut dengan tiga metafungsi komunikasi: ideasional, antarpribadi, dan tekstual.

Dalam bukunya Soelarko (1985) juga menjelaskan tentang potret jurnalistik yang baik, adalah yang dibuat langsung dari tengah-tengah kejadian, yang menjadi berita itu "as it happens". Dalam hal ini, setiap wartawan foto biasanya akan sangat mendambakan datangnya "the golden moment", di mana dia sudah siap dengan segala peralatan teknis dan kemudian subjeknya akan muncul di hadapannya selama satu detik saja dengan segala sifat-sifat beritanya, dan jari dari fotografer akan menekan pelatuk rananya dan tersimpanlah foto yang diinginkannya untuk selama-lamanya.

Barthes (1977) mengungkapkan dalam bukunya Imaji, Musik, Teks bahwa bangunan struktural foto jika di analisis susah untuk berdiri sendiri, foto sekurangkurangnya bersetubuh dengan satu bangunan struktural lain, yaitu teks (judul, penjelasan atau komentar). Oleh karena itu, totalitas informasi dihadirkan oleh dua bangunan struktural berbeda (yang salah satunya merupakan wajah linguistik). Dengan demikian, walaupun foto berita telah lengkap dengan komentar tertulis, penilaian terhadap masingmasing bangunan struktural itu harus dipisahkan. Jika kedua bangunan struktural ini terpisah, kita bisa dapat lebih gampang memahami bagaimana keduanya saling menopang.

Keterangan foto dalam bahasa Inggris disebut caption, memegang peran penting dalam foto berita dan telah menjadi kesatuan dalam foto berita, sebab dari keterangan foto inilah pembaca akan mendapat informasi yang lengkap. Caption foto atau keterangan foto sangat membantu gambar untuk memberikan informasi secara lengkap kepada para pembaca. Caption atau keterangan foto hanya berfungsi sebatas sebagai penambat (anchorage) dan pemancar (relay) belaka. Caption merupakan kalimat pendek yang memberi penjelasan sekilas tentang kejadian pada foto tersebut. Sebuah foto yang baik bisa menjelaskan elemen berita $5 \mathrm{~W}+1 \mathrm{H}$ seperti dikutip Fedler (2005) dalam bukunya Reporting for The Media mengatakan Proponents of public journalism suggest that the routine five W's and H questions (who, what, when, where, why and how) work well but may not be the only ones that work. Caption hadir untuk melengkapi unsur yang tidak ada dalam foto sehingga pesan pada foto dapat tersampaikan kepada audiens.

Foto yang menjadi objek penelitian ini adalah foto-foto jurnalistik tentang bencana yang terjadi pada bulan Maret tahun 2011 di Jepang. National Geographic 
merupakan salah satu wadah fotografer yang cukup senior di ranah media massa tidak hanya cetak maupun daring. Ratusan fotografer dalam dan luar negeri telah mengabadikan foto lewat berbagai tema dan sudut pandang pada saat itu, mereka tidak ingin kehilangan momen yang menjadi daya tarik penikmat foto serta masyarakat yang haus akan informasi.

Adapun peneliti menemukan jurnal ilmiah yang terkait dengan detik-detik tsunami Jepang terjadi, kisah mengharukan dirangkum oleh Lynne Parmenter (2012) dengan judul Community and Citizenship in Post-Disaster Japan: The Roles of Schools and Students. Lynne menjelaskan detik-detik terjadinya tsunami saat anak-anak sedang bersekolah, karena Jepang sangat tanggap dengan bencana tsunami maka banyak anak sekolah yang terselamatkan karena sudah mengerti arahan saat tsunami akan datang.

Penulis juga menemukan arahan tulisan lebih spesifik dari sebuah tesis karya Fahrul Azhar (2015) dari Universitas Trisakti yang berjudul Foto Ikonik Masa Perjuangan Reformasi Indonesia Karya Julian Sihombing: Kajian Pemaknaan Perjuangan Reformasi Indonesia, isi dari tesis ini juga menjelaskan pesan konotatif dan denotatif dalam membaca sebuah foto dengan menggunakan teori Roland Barthes. Selain itu, ada juga tesis dari Rifki Mamduh (2014) yang berjudul Membaca Foto-Foto Jurnalistik Banjir Dahsyat Jakarta (Studi Analisis Semiotik Foto - Foto Jurnalistik Dengan Tema 'Banjir Dahsyatisê. Jakarta' Dalam Situs Berita Online Tribunnews.Com), dengan beberapa karya ilmiah di atas penulis bisa menguatkan tulisan ini dengan pijakan dan referensi yang sudah pernah diteliti sebelumnya, namun penulis mengembangkan beberapa unsur kebaruan pada subfokus yang belum diteliti sebelumnya.

Dalam penelitian ini penulis memilih beberapa shot foto dari berbagai fotografer yang dapat mewakili objek penelitian dengan menggunakan kajian semiotik. Menurut penulis berdasarkan hal yang ditemukan di lapangan mengenai makna dari pesan pada tubuh foto jurnalistik amatlah penting untuk dikaji, hal ini dikarenakan makna yang bisa di dapat dari sebuah foto itu sendiri sangat beragam, di sana memuat pesan teks dan pesan gambar yang bisa diuraikan sebgai pesan yang tersurat dan tersirat, yang dikenal dengan pesan denotatif dan konotatif di kalangan pengkaji semiotik.

Penulis telah mencari kajian pustaka pada beberapa sumber. Peneliti menemukan judul jurnal dan tesis yang serupa, tetapi tak sama dengan tema penelitin yang akan peneliti kaji, salah satunya tesis yang berjudul Membaca Fotografi Prewedding karya Abdul Azis (2011) dari Universitas Airlangga juga menjabarkan bagaimana proses semiotika pada foto dapat dijelaskan, Aziz juga menyebutkan beberapa teori Barthes untuk mengkaci pesan yang ada dalam foto tersebut. Adapun Kurnia Setiawan (2003) dari Universitas Gajah Mada yang menulis tesis dengan judul Semiotika foto jurnalistik: Kajian terhadap foto peristiwa lengsernya Gus Dur di halaman muka harian Kompas dan Republika yang dalam abstraknya menjelaskan bahwa Penelitian ini menggunakan pendekatan semiotik Roland Barthes dan untuk melengkapi pemahaman secara kontekstual, maka digunakan analisis framing dari Robert N. Entman.

Beberapa karya ilmiah yang membahas tentang foto jurnalistik pun banyak mengkaji tentang pesan denotatif dan konotatif yang terkandung di dalamnya, tetapi tidak dapat dipungkiri bahwa teknik pembaca foto seperti ini tidak banyak dipahami oleh kalangan siswa maupun mahasiswa. Menangkap makna teks penyerta gambar (caption) dan menyusun teks penyerta gambar (caption), dengan memperhatikan fungsi sosial, struktur teks, dan unsur kebahasaan yang benar dan sesuai konteks merupakan salah satu rancangan kompetensi dasar yang dipunyai untuk mengembangkan kemampuan berbahasa Inggris pada siswa Sekolah Menengah Atas (SMA) kelas XII yang telah 
diterbitkan oleh Kementrian Pendidikan dan Kebudayaan pada tahun 2016. Oleh karena itu, penelitian ini sangat relevan terhadap kurikulum dan bahan ajar untuk siswa dan mahasiswa perguruan tinggi jurusan jurnalistik.

Faktor utama kajian dalam penelitian ini adalah bagaimana suatu foto jurnalistik dapat diketahui pesannya baik dilihat dari makna yang sebenarnya (denotatif) dan makna yang tersirat (konotatif). Seperti yang penulis sampaikan di atas, bahwa jika kedua bangunan struktural ini terpisah, kita bisa dapat lebih gampang memahami bagaimana keduanya saling menopang, maka penulis memisahkan antara bangunan structural pembaca gambar dalam hal ini adalah foto dan teks, peneliti akan mencoba meneliti sekaligus menginterpretasikan isi pesan dalam foto jurnalistik tersebut dan menyesuaikan dengan pesan teks yang sudah melengkapinya.

\section{METODE PENELITIAN}

Penelitian ini bersifat kualitatif dilakukan dengan menggunakan metode pendekatan analisis semiotik. Metode semiotika pada dasarnya bersifat kualitatif-interpretatif (interpretation), yaitu metode yang memfokuskan pada tanda dan teks sebagai objek kajiannya, serta bagaimana peneliti menafsirkan dan memahami kode (decoding) di balik tanda dan teks tersebut. Metode analisis teks (textual analiysis) adalah salah satu dari metode interpretatif tersebut (Piliang, 2003).

Dari data yang peneliti dapatkan, kemudian akan dikaitkan dengan objek penelitian untuk kemudian dianalisis dan mendapatkan hasil serta disajikan dalam bentuk uraian deskriptif. Kemudian dicocokan apakah antara foto dan teks caption ada kesamaan secara garis besar dengan apa yang sudah dianalisis menggunakan kajian semiotik.

Semiotika memiliki cara pandang yang unik dengan memahami semua hal sebagai tanda. Dengan kacamata semiotika, peneliti ingin melihat secara tajam tanda dan relasi tanda apa yang terdapat dalam rangkaian foto National Geographic. Peneliti akan melakukan kajian dengan dua tahapan utama, yaitu melihat makna denotatif dan konotatif yang masing-masing memiliki proses sendiri. Menurut Barthes (2010), saat menganalisis foto secara utuh kita akan menemukan tiga jenis pesan: pesan linguistik (linguistic message), pesan iconic terkodekan, dan pesan ikonik yang tak terkodekan. Pesan harfiah/pesan ikonik tak berkode (non-coded iconic message), sebagai sebuah analogon yang berada pada tataran denotasi citra yang berfungsi menaturalkan pesan simbolik, sedangkan pesan simbolik/pesan ikonik berkode (coded iconic message), sebagai analogon yang berada pada tataran konotasi yang keberadaannya didasarkan atas kode budaya tertentu atau familiaritas terhadap streotip tertentu.

\section{HASIL DAN PEMBAHASAN}

Dalam perjalanan penelitian, penulis juga menemukan tesis yang sesuai dengan kajian yang sedang diteiti, salah satunya tesis dari sebuah tesis karya Fahrul Azhar (2013) dari Universitas Trisakti yang berjudul Foto Ikonik Masa Perjuangan Reformasi Indonesia Karya Julian Sihombing Kajian Pemaknaan Perjuangan Reformasi Indonesia, isi dari tesis ini juga menjelaskan pesan konotatif dan denotatif dalam membaca sebuah foto dengan menggunakan teori Roland Barthes, dengan beberapa karya ilmiah diatas penulis bisa menguatkan tulisan ini dengan pijakan dan referensi yang sudah pernah diteliti sebelumnya, namun penulis mengembangkan beberapa unsur kebaruan pada subfokus yang belum diteliti sebelumnya.

Adapun peneliti menemukan jurnal ilmiah yang terkait dengan detik-detik tsunami Jepang terjadi, kisah mengharukan dirangkum oleh Lynne Parmenter (2012) 
dengan judul Community and Citizenship in Post-Disaster Japan: The Roles of Schools and Students. Lynne menjelaskan detik-detik terjadinya tsunami saat anak-anak sedang bersekolah, karena Jepang sangat tanggap dengan bencana tsunami maka banyak anak sekolah yang terselamatkan karena sudah mengeti arahan saat tsunami akan datang. Dari jurnal inilah penulis juga dapat merasakan kejadian yang terjadi saat itu, karena dari artikel tersebut dijelaskan bagaimana gempa dan ombak menghantam dengan cepat saat anak-anak sedang bersekolah.

\section{Pesan Konotatif}

\section{Foto National Geographic 1}

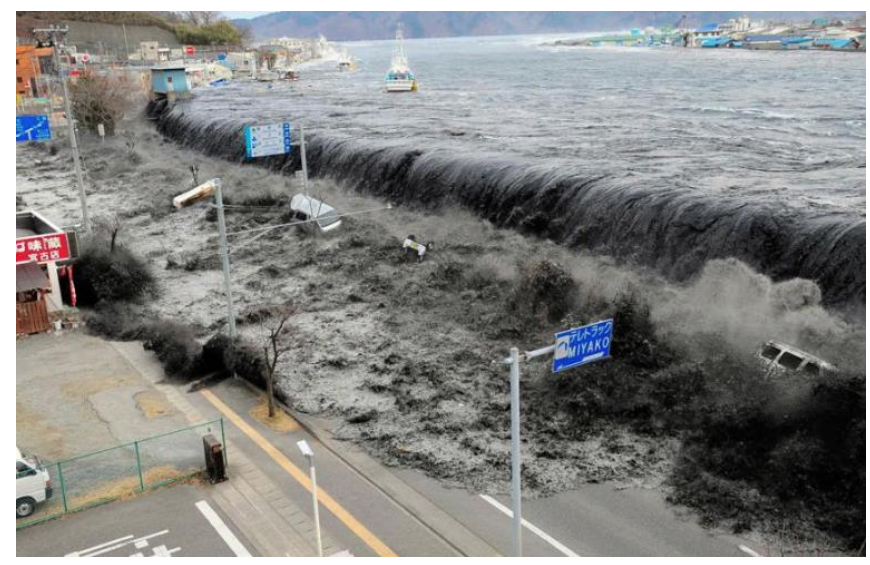

Gambar 1 National Geographic 1

Sumber: Dokumen Pribadi

Makna konotasi yang dianalisis dengan enam aspek menurut Barthes, yaitu untuk memahami makna konotasi dalam sebuah foto, dalam metode Barthes disebut dengan tahap konotasi kognitif, yaitu makna yang dibangun atas dasar imajinasi paradigmatik. Selain pemahaman kultural untuk menambah informasi yang ada di dalam foto, juga dapat diperoleh dengan mengamati beberapa perkembangan prosedur yang memengaruhi gambar sebagai analogon. Prosedur tersebut dikategorikan menjadi enam, antara lain:

Trict effect : Trict effect merupakan manipulasi gambar secara artificial, dengan maksud membuat foto menjadi lebih baik lagi tanpa mengubah isi foto yang sebenarnya, dalam foto ini tidak ada manipulasi apa pun, dapat dinyatakan foto ini asli, karena dalam foto National Geographic fotografer haruslah menampilkan karya yang orisinil tanpa penmbahan efek yang berlebihan.

Pose : Pada foto pertama diambil dengan format gambar horizontal. Pose, dipahami sebagai gaya, posisi, ekspresi dan sikap objek foto. Dalam foto dengan peristiwa bencana, kita tidak akan menemukan pose di dalamnya. Sebab, peristiwa alam yang menjadi objek foto tidak terdapat unsur gaya, ekspresi ataupun sikap.

Objek : Foto ini menunjukan bahwa kejadian ini terjadi di Jepang tepatnya daerah Miyako, karena terdapat plang nama tempat yang akan diterjang ombak. Keseluruhan elemen yang ada dalam satu bingkai foto sebenarnya bisa dikatakan sebagai objek foto. Namun, terkait dengan objek dalam membaca foto di sini, object dipahami sebagai 
Fotogenia

Estetisme

satu subjek utama (point of interest) dalam satu bingkai foto. Point of interest dalam fotografi dipahami penulis merupakan bagian yang paling menarik atau menonjol dalam sebuah foto. Point of Interest (POI) atau subjek utama dalam data foto 1 adalah pada gulungan ombak yang datang dari tengah laut.

Pesan konotasi yang terdapat dalam foto ini adalah pencahayaan yang sangat baik karena diambil di luar ruangan. Representasi pada foto ini dari segi komposisi amatlah kuat dan memberikan nilai informasi. Foto dari segi teknik pengambilannya meliputi lighting (pencahayaan), exposure (ketajaman foto), bluring (keburaman), panning (efek kecepatan), moving (efek gerak), freeze (efek beku), angle (sudut pandang pengambilan objek). Apabila dilihat dari teknik pengambilan gambarnya, apa yang tampak dalam data foto 1 terlihat foto diambil di luar ruangan dengan memanfaatkan cahaya alami yaitu matahari (available light). Adanya perbedaan ketajaman objek pada latar depan (foreground) dan latar belakang (background) mengindikasikan foto diambil menggunakan teknik ruang tajam sempit. Melihat POI yang ada dalam foto memberi indikasi foto diambil dengan sudut pandang di atas mata manusia atau dalam istilah angle fotografi disebut dengan high angel level. Dengan penggunaan angle ini, secara teknik tidak terlalu menimbulkan pesan tertentu. Perlu juga diketahui, pemilihan angle dalam fotografi sedikit banyak juga dapat memberi pesan tertentu, dan juga biasanya dari angle yang digunakan fotografer, kita dapat melihat bagaimana sudut pandang seorang fotografer dalam menampilkan sebuah foto.

Aestheiscism atau komposisi merupakan susunan dari berbagai objek atau gambar yang mempunyai dua sifat saling bertentangan, bisa membangun gambar namun juga bisa mengacaukan gambar. Dalam hal ini pengambilan gambar sangatlah dramatis, gelombang tsunami yang menghantam merupakan hasil tanpa rekayasa dalam foto jurnalistik.

Sintaksis : Foto ini ingin menyampaikan bahwa tsunami di Jepang ini amatlah dahsyat dilihat dari ombak dan angina sangat kencang sampai menyapu banyak benda di jalanan dan sekitarnya.

\section{Foto National Geographic 2}

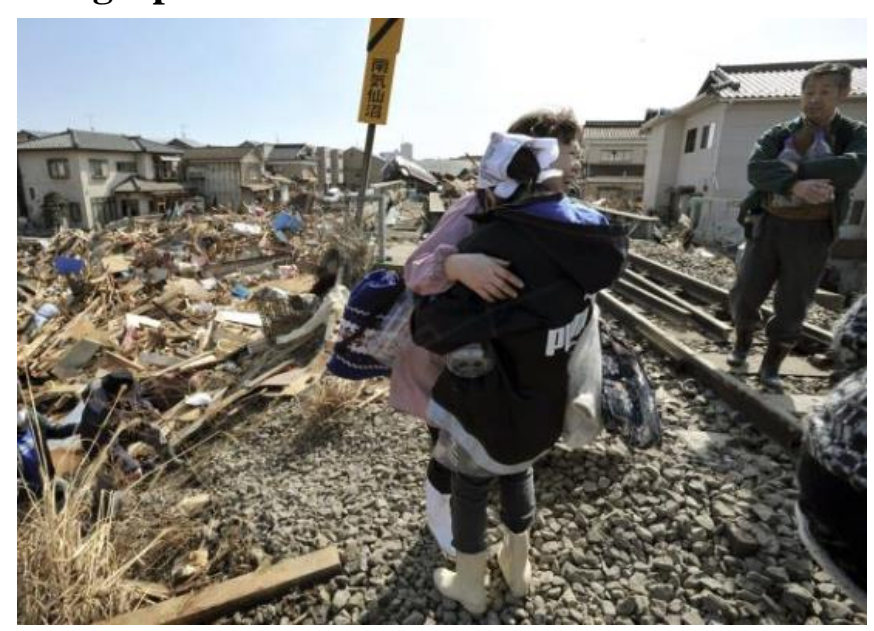

Gambar 2 National Geographic 2

Sumber: Dokumen Pribadi 
Untuk memahami makna konotasi dari sebuah foto, dalam metode Barthes disebut dengan tahap konotasi kognitif, yaitu makna yang dibangun atas dasar imajinasi paradigmatik. Selain pemahaman kultural untuk menambah informasi yang ada di dalam foto, juga dapat diperoleh dengan mengamati beberapa perkembangan prosedur yang memengaruhi gambar sebagai analogon. Prosedur tersebut dikategorikan menjadi enam, antara lain:

Trick effect : Tidak ada manipulasi papun dalam foto ini, dapat dinyatakan foto ini asli. Trick effect dipahami sebagai upaya memanipulasi gambar sampai tingkat yang berlebihan untuk menyampaikan maksud pembuat berita. Pada data foto 2, penulis tidak menemukan indikator yang menunjukkan adanya trick effect. Sebab dari apa yang tampak dalam foto 2 merupakan hasil jepretan murni fotografer pada saat korban tsunami sedang.

Pose : Foto diambil dengan teknik full shot serta gaussian blur di belakangnya. Dua orang wanita berpelukan dan satu orang berdiri memandang mereka dengan latar belakang buram (blur) sehingga terlihat lebih dramatis dan seolah-olah ingin membagi cerita atas pertemuan dua orang tersebut.

Objek : Plang distrik berwarna kuning yang belum hancur sebagai tanda yang bisa dijadikan sumber informasi, dan hancurnya rumah berganti dengan puing-puing bangunan menandakan dimana kota tersebut yang terhantam tsunami, dan tiga orang berkumpul di tengah kehancuran kota mereka dan meratapinya saling berbagi.

Fotogenia : pesan konotasi yang terdapat dalam foto ini adalah pencahayaan yang sangat baik karena diambil di luar ruangan. Representasi pada foto ini dari segi komposisi amatlah kuat dan dramatis.

Estetisme : Estetika komposisi gambar pada foto 2 juga memiliki kekuatan pesan yang menarik. Pengambilan gambar yang menitikberatkan pada dua orang perempuan yang sedang berduka di tengah puing-puing sisa tsunami.

Sintaksis : foto ini ingin menyampaikan bahwa kesedihan yang menimpa banyak penduduk yang ada di wilayah tersebut. Kehilangan yang teramat dalam dapat terlihat dari raut wajah penduduk yang berduka.

\section{Pesan Denotatif}

1. Foto National Geographic 1

Denotasi merupakan relasi antara penanda dengan petanda dalam sebuah tand seperti yang sudah diungkapkan dalam pembahsan sebelumnya, serta tanda dengan acuan realitas eksternalnya. Untuk mengungkap makna denotatif sebuah foto dapat diketahui pada tahap perseptif, yaitu melakukan transformasi gambar ke kategori verbal atau verbalisasi gambar.

Menjelaskan denotasi terhadap karya fotografi hanya menyatakan apa yang ada dan terlihat dalam gambar, tanpa memberi pemaknaan subjektif. Artinya, denotasi dalam foto hanya akan membicarakan tentang apa yang difoto, tidak lebih dari itu. 
Menambahkan atau mengurangi baik secara objektif maupun anggapan subjektif terhadap apa yang tampak dalam foto adalah hal yang dilarang ketika menjelaskan tentang makna denotasi pada foto.

Dalam data foto pertama, didapati objek (analogon) apa saja yang terdapat dalam foto tersebut, antara lain:

a. Spot Photo, foto yang dibuat dari peristiwa tidak terjadwal atau tidak terduga yang diambil oleh si fotografer langsung di lokasi kejadian. Pengambilan gambar dengan menggunakan teknik full shot agar terlihat jelas peristiwa yang sedang terjadi saat itu. Dibutuhkan keberuntungan pada fotografer dalam hal posisi dan keberadaannya, serta keberaniannya saat membuat foto. Memperlihatkan emosi subjek yang difotonya sehingga memancing juga emosi pembaca.

b. Beberapa kapal yang masih ada di tengah laut

c. Ombak besar yang dating dari arah laut lepas

d. Terlihat beberapa mobil yang terhempas oleh ombak besar

e. Sign yang menunjukkan tempat terjadinya tsunami

f. Jalan yang akan tersapu dengan ombak

g. Ombak besar terlihat akan menghantam sebuah ruko

h. Makna denotasi yang didapat dengan memperhatikan beberapa analogon yang ada mengungkapkan, secara verbal dapat kita katakan dalam gambar ini Sebuah terjangan arus kencang dari lautan yang menghancurkan plang, rambu, tiang listrik, mobil yang ada di jalanan.

2. Foto National Geographic 2

Dalam gambar data foto kedua dapat diamati beberapa analogon yang berbentuk objek dari makna denotatif foto tersebut, antara lain:

a. Seorang lelaki paruh baya sedang melihat kearah dua orang wanita di depannya terlihat raut kesedihan melihat ke sisi dua orang perempuan yang sedang berpelukan.

b. Dua orang wanita yang salah satunya paruh baya, sedang memeluk seorang yang sedang bersedih.

c. Puing-puing bangunan setelah surut ombak tsunami.

\section{Teks Caption Foto}

1. Caption Foto Jurnalistik 1

A tsunami crashes over a street in Miyako City, Iwate Perfecture, in northeastern Japan on March 11. Gelombang Kehancuran. Sebuah Tsunami menghancurkan sepanjang jalan di Kota Miyako, wilayah Iwate, di timur laut Jepang pada 11 Maret. Dalam teks foto national geographic pertama dapat diketahui caption yang ditulis menggunakan kalimat deskriptif yang memuat informasi kejadian saat itu, dan kalimat tersebut menggunakan simple present tense. Terdapat unsur $5 \mathrm{~W}$ dan menginterpretasi sebuah $\mathrm{H}$ dalam caption tersebut. Who, terdapat dalam kalimat Population of Miyako City, kemudian What, apa yang menyebabkan kejadian tersebut A tsunami crash over a street, Where, dimana kejadian berlangsung Miyako City, When, kapan kejadian berlangsung, March 2011 dan Why, kenapa kejadian ini bisa terjadi, disaat inilah informasi lebih yang diperlukan seorang pembaca, Tsunami bisa terjadi karena Dengan melihat penyebab terjadinya tsunami tersebut, maka gempa yang terjadi di jepang dengan kekuatan 8,9 merupakan tsunami yang mengakibatkan gelombang besar karena patahan di dasar laut. 
Berdasarkan penjabaran pada sub bab sebelumnya, yaitu hasil penelitian makna denotatif dan konotatif, dapat disimpulkan bahwa teks foto caption pada gambar Tsunami Jepang National Geographic yang pertama terdapat kesamaan makna dengan caption yang sudah ada, berarti kajian semiotik Roland Barthes dalam membaca pesan foto dan dicocokan dengan teks caption foto terdapat kesamaan, namun apabila pembaca atau penikmat foto tidak memiliki pengetahuan yang cukup mengenai berita kejadian tersebut sebelumnya, maka akan mengalami kesulitan untuk menemukan informasi lebih lanjut, seperti tanggal dan di mana tepatnya tempat kejian berlangsung.

\section{Caption Foto Jurnalistik 2}

Tearful Reunion. Tsunami survivors embrance to celebrate being alive in the destroyed city of Kesennuma, Miyagi Perfecture, on March 11. (Fotografer: Kimimasa Mayama/EPA). Berkumpul dalam keharuan. Korban selamat dari tsunami saling merangkul karena selamat dari kehancuran Kota Kesennuma, wilayah Miyagi, pada tanggal 11 Maret.

Dalam teks foto national geographic kedua dapat diketahui caption yang ditulis menggunakan kalimat deskriptif yang memuat informasi kejadian saat itu, dan kalimat tersebut menggunakan simple present tense. Terdapat unsur $5 \mathrm{~W}$ dan menginterpretasi sebuah $\mathrm{H}$ dalam caption tersebut. Who, terdapat dalam kalimat Population of Miyako City, kemudian What, apa yang menyebabkan kejadian tersebut A tsunami crash over a street, Where, dimana kejadian berlangsung Miyako City, When, kapan kejadian berlangsung, March 2011 dan Why, kenapa kejadian ini bisa terjadi tsunami.

\section{Kesesuaian Pesan Teks dan Pesan Gambar pada Foto}

Kesesuaian makna pesan teks dan pesan gambar didapat setelah penulis menelaah pesan yang ada dalam foto jurnalistik dengan menggunakan teori semiotik Roland Barthes, kemuadian mengkaji teks caption berbahasa Inggris yang diterjemahkan ke dalam bahasa Indonesia. Pada foto pertama dalam pemaknaan pesan denotasi dan konotasi dari hasil penelitian terdapat di dalamnya beberapa kalimat yang sesuai dengan teks caption yang sudah terdapat pada foto. Contoh dalam pesan konotatif terdapat tempat terjadinya di daerah Miyako karena ada sign yang menandakan di mana tempat itu terjadi, dan kata tsunami yang terlihat pada pesan denotatif, kemudian ditemukan kata "ombak besar menghantam", jadi dapat ditarik kesimpulan pada foto pertama dengan caption foto " $A$ tsunami crashes over a street in Miyako City, Iwate Perfecture, in northeastern Japan on March 11 " adanya kemiripan dengan kajian menggunakan denotatof dan konotatif, hanya saja pengetahuan pembaca dibutuhkan untuk mengetahui informasi lebih lanjut tentang tanggal atau tahun beapa peristiwa itu terjadi.

Pada foto kedua dalam pesan denotatif mnyampaikan bahwa "terlihat lelaki paruh baya dan dua wanita sedang berpelukan dengan raut muka bersedih, serta adanya puingpuing di sekitar mereka" kemudian pesan konotatif "dalam foto ini tidak ada manipulasi foto yang berlebihan, dengan teknik full shot foto ini diambil, terdapat plang kuning yang merupakan sumber informasi untuk menulis caption foto, pencahayaan dari foto ini terbilang baik karena diambil di luar ruangan. Pesan yang ingin disampaikan pada foto ini bahwa kesedihan yang terlihat dari raut wajah dua orang yang sedang berpelukan yang terlihat kehilangan dan berduka" kemudian caption yang tertera adalah Tearful Reunion. Tsunami survivors embrance to celebrate being alive in the destroyed city of Kesennuma, 
Miyagi Perfecture, on March 11. Ada beberapa pesan yang masuk ke dalam teks caption foto yang sudah diberikan oleh fotografer dengan analisis denotatif dan konotatif. Jadi, ada kesesuaian pesan antara pesan konotatif, denotaif dan caption foto.

\section{SIMPULAN}

Tulisan ini telah menjelaskan bagaimana menjabarkan dan mencocokkan antara gambar dengan caption melalui kajian semiotika dengan menjabarkan makna denotatif dan konotatifnya pada gambar dan teks dengan pemaknaan semiotika Roland Barthes. Dengan pemaknaan semiotika Roland Barthes dalam membaca sebuah foto dapat mempermudah kita dalam menulis sebuah caption foto, karena kita diberikan pengetahun hal apa yang perlu ditelaah terlebih dahulu sebelum membaca foto. Dalam dunia serba digital dengan penuh gambar kita tidak bisa mengandalkan penguasaan dan pemahaman kita pada satu mode saja untuk memahami pesan yang disampaikan teks secara menyeluruh dan lebih 'benar'. Kita harus menguasai cara membaca gambar, sesuatu yang selama ini dianggap tak cukup diwakili oleh seribu kata. Paling tidak, dengan menguasai dan memahami alat analisis ini kita bisa mendeskripsikan gambar, ilustrasi, lukisan dan desain dengan lebih baik tanpa harus bergantung pada apa yang disampaikan oleh para curator fotografer, lukisan, pembuat ilustrasi, atau disainer.

Kendala yang ditemui pada saat mencocokkan foto dari pesan denotasi dan konotasi adalah ketika pembaca tidak mengetahui berita lengkap mengenai tsunami yang terjadi di Jepang, ilmu mengenai huruf kanji pun merupakan nilai lebih ketika ingin membaca foto, mungkin itu bisa menjadi masukan untuk mengetahui apa yang tertulis di dalamnya.

Mungkin di masa datang bukan lagi pemahaman kita pada arti kata-kata saja, tapi pemahaman kita pada apa arti kata dan gambar, imej, dengan pemahaman kita pada imej memainkan peranan yang lebih besar dan menentukan.

\section{DAFTAR PUSTAKA}

Azhar, F. (2015). Foto ikonik masa perjuangan reformasi indonesia karya Julian Sihombing kajian pemaknaan perjuangan reformasi Indonesia. (Tesis). Universitas Trisakti.

Aziz, A. (2011). Membaca fotografi prewedding dengan semiotika sebagai representasi budaya etnik masyarakat urban. (Tesis). Fakultas Ilmu Sosial dan Ilmu Politik Universitas Airlangga.

Barthes, R. (2002) Elements of semiology, (Terj.) St.Sunardi, Semiotika Negativa. Yogyakarta: Kanal.

Barthes, R. (2010). Imaji, Musik, Teks, (Terj.) oleh Agutinus Hartono Yogyakarta: Jalasutra.

Barthes, R. (1977). Image, music, text. London: Fontana Press.

Fedler, F et al. (2005). Reporting for the media. New York: Oxford. 
Goodnow, T. (2010) Visual Bias in Time's "The Great Divide": A Semiotic Analysis of Clinton and Obama Photographs. American Behavioral Scientist, 54 (406), DOI: $10.1177 / 0002764210381865$

Graham, C. (1997). The photograph. New York: Oxford.

Mamduh, R. (2014). Membaca foto-foto jurnalistik banjir dahsyat Jakarta (studi analisis semiotik foto-foto jurnalistik dengan tema 'banjir dahsyatisç. Jakarta' dalam Situs Berita Online Tribunnews.com pada Januari 2013) http://repository.unair.ac.id/38687/

Parmenter, L. (2012). Community and citizenship in post-disaster Japan: The Roles of Schools and Students, 11 (3), (C) JSSE 2012 ISSN 1618-5293.

Piliang, Y. A. (2003). Hipersemiotika semiotikai tafsiri culturali studies atas Matinyaimakna. Bandung: Jalasutra.

Saussure, F. (1959). Course in general linguistics. New General Linguistics. New York: The Philosophical Library,inc

Setiawan, K. (2003). Semiotika foto jurnalistik: Kajian terhadap foto peristiwa lengsernya Gus Dur di halaman muka harian Kompas dan Republika (Tesis). S2 Fakultas Pengkajian Seni Pertunjukan dan Seni Rupa Universitas Gajah Mada.

Soelarko, R.M. (1985). Pengantar foto jurnalistik, Bandung: PT Karya Nusantara.

Viranda, L. dkk. (2018). Manajemen produk media Kompas. Com untuk bersaing di era generasi milenial. http://jurnal.unpad.ac.id/kajian-jurnalisme/article/view/21074. 